\title{
EVANS SOBRE SCHEINGEDANKE
}

\section{José Renato Salatiel ${ }^{1}$}

Universidade Federal do Espírito Santo (UFES)

https://orcid.org/0000-0001-5858-1248

E-mail: jose.salatiel@ufes.br

\section{RESUMO:}

Gareth Evans propôs, em The Varieties of Reference, uma teoria de proposições singulares que incorporava tanto as especulações de Frege a respeito do sentido (Sinn) quanto a estrutura proposicional dependentedo-objeto de Russell. Para isso, defendeu que proposições que contém termos singulares vazios, ou seja, cujo indivíduos denotados são inexistentes, não expressam pensamentos deste tipo. Nesta situação, alguém que enuncie uma sentença que contém termos singulares vazios só pode expressar pensamentos aparentes (Scheingedanke). A interpretação de Evans foi criticada por trabalhos de filósofos como Bell (1990), Geirsson (2002) e Sainsbury (2002). Neste artigo retomarei esse debate para reavaliar as objeções ao argumento de Evans sobre o conceito de Scheingedanke. Defenderei que essas críticas, ainda que fundamentadas em uma leitura cuidadosa de Frege, são insuficientes para desqualificar a tese de Evans. Pelo contrário, sugiro que seu projeto seria melhor apreciado em um âmbito epistêmico, não puramente exegético. Essa me parece ser uma abordagem mais próxima das intenções do autor ao elaborar sua teoria sobre pensamento singular.

PAlaVRaS-CHAVE: Filosofia da linguagem; Teorias da referência; Pensamento singular; Evans; Frege; Epistemologia.

\section{EVANS ON SCHEINGEDANKE}

\begin{abstract}
:
Gareth Evans has proposed, in The Varieties of Reference, a theory of singular propositions which embody both Frege's speculations about sense (Sinn) and Russell's propositional object-dependence structure. For this purpose, he maintained that propositions containing empty singular terms, i.e., whose putatively denoted objects are non-existent, do not express any thoughts of this type. In this situation, someone who utters a sentence that contains an empty singular term can only express an apparent thought (Scheingedanke). Evans' interpretation of Frege was criticized in works of philosophers such as Bell (1990), Geirsson (2002) and Sainsbury (2002). In this article, I aim to continue this debate and review the objections against Evan's argument regarding the concept of Scheingedanke. I maintain that, though the work of these critics is based on a careful reading of Frege, it is not enough to dismiss Evan's thesis. Instead, I claim that his theory would be better appreciated in an epistemic, not purely exegetical, sphere. This appears to me to be closer to the author's intended approach regarding the theory of singular thoughts.
\end{abstract}

KEYWORDS: Philosophy of language;Ttheories of reference; Singular thoughts; Evans; Frege; Epistemology.

1 Doutor em Filosofia pela Pontifícia Universidade Católica de São Paulo (PUC/SP), São Paulo - SP, Brasil. Professor da Universidade Federal do Espírito Santo (UFES), Vitória - ES, Brasil.

SALATIEL, José Renato. Evans sobre Scheingedanke. Griot : Revista de Filosofia, Amargosa - BA, v.19, n.2, p.7186, junho, 2019. 


\section{Introdução}

Pensamentos aparentes ocorrem quando, acreditando que estamos tendo um certo pensamento singular (dependente-do-objeto), na verdade temos apenas a ilusão de que temos um pensamento desse tipo. Isso acontece quando, ao proferir uma sentença na forma "Este $a$ é F", o "a" denota um indivíduo que, de fato, não existe.

Gareth Evans desenvolveu essa teoria em The Varieties of Reference (1982) a partir do conceito de Scheingedanke, usado por Frege e comumente traduzido como mock thoughts (pensamentos simulados). Desde então, vem recebido diversas críticas.

Este artigo propõe analisar o a noção de Scheingedanke na obra de Evans, em especial no o capítulo 1 ("Frege"). Mostrarei como a concepção de cenários céticos de pensamentos aparentes é elaborada pelo autor a partir de um argumento central, que ele ampara em uma interpretação controversa da teoria dos sentidos de Frege.

No primeiro capítulo defino alguns conceitos importantes e estabeleço um panorama teórico do debate em Russell e Frege para, no seguinte, delinear a noção de proposições neofregeanas de re e de pensamento aparente de Evans. No terceiro capítulo examino as réplicas de três dos principais debatedores, Bell (1990), Geirsson (2002) e Sainsbury (2002). Concluo que as objeções expostas por esses autores são insuficientes para desqualificar a teoria de Evans com base em uma suposta leitura enviesada de Frege, e que a proposta do filósofo inglês deveria ser reavaliada em um âmbito epistêmico, não puramente exegético.

\section{Pensamento singulares: Russell e Frege}

Pensamento, segundo uma concepção e tradição semânticas, é entendido como um conteúdo mental. Nisso difere de uma abordagem psicológica, que compreende pensamento como um episódio mental. A distinção entre estas duas esferas, lógica e psicológica, foi demarcada por Frege, para quem o ato de pensar é uma ideia (Vorstellung), interna e subjetiva, enquanto o pensamento (Gedanke) é a apreensão de um sentido, externo e objetivo. ${ }^{2}$ Por isso, considera-se que esse conteúdo mental é estruturado como uma proposição. Proposições, por seu turno, são sentenças que podem ser verdadeiras ou falsas e que são independentes de um pensamento particular, ou seja, podem ser asseridas por diferentes sujeitos.

Pensamento singular é um tipo particular de pensamento, expresso por meio de proposições singulares. Essa definição, contudo, traz sérias dificuldades filosóficas.

Para Russell (1989b), há dois tipos de proposições que correspondem a duas formas de pensamento: gerais e singulares. Pensamento singular (ou, como é geralmente chamado, de re) é definido, seguindo uma proposta russelliana, como sendo aquele que se

\footnotetext{
${ }^{2}$ Frege define pensamento em oposição à ideia em termos de uma dicotomia objetivo/subjetivo, externo/interno e público/privado, com o propósito de demarcar o que é lógico e o que é psicológico. Isso aparece em "Sobre o sentido e a referência" (FREGE, 2009a), mas, em detalhes, em "O pensamento" (FREGE, 2002).
}

SALATIEL, José Renato. Evans sobre Scheingedanke. Griot : Revista de Filosofia, Amargosa - BA, v.19, n.2, p.7186, junho, 2019. 
refere diretamente ao objeto, em contraste com um pensamento descritivo (ou de dicto), que se refere indiretamente ao objeto, mediante suas propriedades (cf. BACK, 1987; JESHION, 2010).

Suponha que as seguintes sentenças possuem o mesmo referente: (1) "A cadeira do escritório de João é marrom" e (2) "Esta cadeira é marrom". No primeiro caso, pensamos conceitualmente, por meio de uma descrição definida ("A cadeira do escritório de João"), na qual um objeto se torna o referente da sentença se ele satisfaz àquela descrição. Já no segundo, me refiro diretamente ao objeto particular percebido por meio de um pronome demonstrativo ("esta"), independentemente de propriedades que lhe possam ser atribuídas. Em suma, na sentença (1) o referente satisfaz ou não a descrição "a cadeira do escritório de João", enquanto em (2) o pronome "esta" estabelece uma relação direta entre o pensamento e o objeto de referência.

O que caracteriza o pensamento singular é o fato de ele ser uma proposição singular "russeliana", nas quais o objeto e suas propriedades fazem parte da estrutura da proposição. ${ }^{3}$ Como consequência, considerando uma proposição na forma "a é $F$ ", onde "a" é uma constante lógica, quando essa constante falha em denotar um indivíduo, a sentença falha em expressar um uma proposição. O que qualifica uma proposição singular russeliana, portanto, é aquilo que Evans (1982, p. 43) expressou no seguinte critério: se um termo referencial nada denota, a sentença que o contém expressa um pensamento? Se sim, ela é, na verdade, uma descrição definida, cuja forma lógica é uma fórmula quantificada complexa (RUSSELL, 1989a); se não, então pode-se dizer que se trata de um nome genuíno. Um pensamento singular, deste modo, é dito ser dependentedo-objeto, pois no caso em que não há referente, não há conteúdo algum a ser pensado. ${ }^{4}$

Porém, essa concepção de pensamento singular dependente-do-objeto não atende ao que Evans chama de critério intuitivo de diferença (1982, p. 18): dois termos singulares diferentes, que se referem ao mesmo objeto, podem ser pensados contraditoriamente em uma mesma sentença, como neste célebre exemplo de Frege: (1) A estrela da manhã é a estrela da manhã; e (2) A estrela da manhã é a estrela da tarde. Ambos os termos, "estrela da manhã" e "estrela da tarde", denotam o planeta Vênus, mas enquanto a sentença (1) é tautologicamente verdadeira, (2) pode ser considerada falsa sem autocontradição. ${ }^{5}$

Frege, em trabalhos complementares a Begriffschrift (1879), defendeu uma posição sobre proposições singulares muito próxima daquela sustentada por Russell. Segundo essa primeira teoria da referência de Frege, se um nome é vazio, a sentença (função) na qual ele ocorre como um argumento falha em ter uma referência, isto é, um valor-de-verdade. Ele deixou isso claro em exemplos como o seguinte:

\footnotetext{
${ }^{3}$ Devemos entender esse caráter constitutivo do objeto na proposição no contexto da filosofia de Russell, para quem não são objetos físicos, mas dados dos sentidos que são objetos de familiaridade.

${ }_{4}^{4}$ Segundo Russell, a condição para que o sujeito tenha um pensamento singular é que ele tenha um conhecimento direto, por familiaridade (acquaintance) do objeto e suas propriedades; proposições gerais, ao contrário, expressam um conhecimento descritivo (RUSSEL, 1977).

${ }^{5}$ A teoria das descrições de Russell resolveria o dilema tratando esses termos não como nomes genuínos, mas como descrições definidas "disfarçadas".
}

SALATIEL, José Renato. Evans sobre Scheingedanke. Griot : Revista de Filosofia, Amargosa - BA, v.19, n.2, p.7186, junho, 2019. 
A sentença "Léo Sachse é um homem" só é a expressão de um pensamento caso "Léo Sachse" designe algo. Do mesmo modo, a sentença "Esta mesa é redonda" só será a expressão de um pensamento caso as palavras "esta mesa" designem algo para mim, caso elas não sejam palavras vazias. ( $\mathrm{PH}$, p. 174; $\mathrm{cf}$. p. 60$).^{6}$

Frege parece aqui adotar a posição de um termo singular russeliano (proposição dependente-do-objeto), no sentido em que, se alguém enuncia uma sentença contento um termo singular vazio, isto é, que não possui um referente, então falha em expressar um pensamento.

Mas, para lidar com questões como o dilema anterior, envolvendo sentenças com o mesmo referente e diferentes valores cognitivos, Frege introduz, em "Sobre o sentido e a referência" (1892), a distinção semântica entre sentido (Sinn) e valor semântico (Bedeutung) $)^{7}$, na qual o valor semântico de uma sentença corresponde a seus valores-deverdade, enquanto sentido é o pensamento (Gedanke) que ela expressa. A principal mudança teórica aqui é que a função dos nomes não é mais introduzir o objeto de referência, mas apresentar esse objeto de um modo (de um certo ponto de vista, para usar outra metáfora) particular na proposição, configurando, assim, a seguinte tese semântica (FREGE, 2009a, p. 131):

\section{Tese (1): Sentido (Sinn) é o modo de apresentação do objeto.}

A teoria apresentada em "Sobre o sentido e a referência" permite a Frege resolver o problema: duas sentenças com termos singulares que denotam o mesmo objeto poderiam veicular diferentes valores cognitivos (sentido). Assim, as sentenças "Sirius é a estrela mais brilhante no céu" e "A estrela do cão é a estrela mais brilhante no céu", possuem o mesmo valor semântico (referindo-se a um corpo celeste), mas sentidos diferentes, ou seja, diferentes modos de apresentação daquele objeto (FREGE, 2009, p. $131)$.

A teoria do sentido resolveria ainda o problema dos nomes sem portadores, sentenças cujos termos singulares não possuem referente e, deste modo, não possuem valor-de-verdade, como por exemplo, em "Pégaso é branco". A questão é que, mesmo que "Pégaso" não tenha referente, a sentença é perfeitamente entendida, o que não poderia ser explicado por uma semântica puramente referencial.

A solução para o problema dos nomes vazios marcaria uma distinção entre a concepção semântica anterior de Frege, pré-1892. Agora, o que o sujeito precisa é

\footnotetext{
6 Tradução de Paulo Alcoforado (FREGE, 2009b, p. 208). "Dezessete sentenças básicas da lógica" foi publicado postumamente e não há consenso sobre a data de sua publicação, variando de 1906 (data conferida pelo editor original, mas pouco provável) até anterior a 1892, entre 1876 e 1877. Evans considera a data da publicação como sendo contemporânea ao "Diálogo com Pünger sobre a existência" (1884) (cf. EVANS, 1982, p. 12, n. 9).

7 Bedeutung é traduzido de diferentes maneiras para o português, ora como referência (mais comum), ora como significado. Optei por valor semântico para demarcar que nem sempre Frege quer dizer, com Bedeutung, um objeto denotado (referente), o que é importante para a presente discussão. Usaremos, alternadamente, Sinn no lugar de sentido sempre que se fizer necessário para evitar a polissemia da palavra em português. Por fim, tratamos no presente texto sentença e proposição como sinônimos, sem prejuízo à pesquisa.
}

SALATIEL, José Renato. Evans sobre Scheingedanke. Griot : Revista de Filosofia, Amargosa - BA, v.19, n.2, p.7186, junho, 2019. 
exercer os conceitos "Pégaso", "ê" e "branco" para pensar a proposição, cujo objeto satisfaz àquela descrição articulada conceitualmente. ${ }^{8}$ Frege admite, contrariando sua doutrina anterior, a existência de nomes próprios simulados (Scheineigenname):

Pode-se talvez admitir que uma expressão sempre tenha um sentido, caso seja gramaticalmente bem construída, e desempenhe o papel de nome próprio. Mas isso não quer dizer que sempre exista uma referência [Bedeutung] correspondente ao sentido. As palavras "o corpo celeste mais distante da terra" têm um sentido, mas é muito duvidoso que também tenham uma referência [...] Portanto, apreender um sentido nunca assegura a existência de sua referência. (Ibidem, p. 133).

E, pelo princípio de composicionalidade", infere-se que a sentença "Pégaso é branco", sendo composta de um nome vazio, também não teria um valor semântico. Não teria, portanto, valor-de-verdade? Frege, mais uma vez, parece confiante que em alguns contextos específicos - aqueles em que não há compromisso com a busca da verdade, como a ficção e a mitologia (Ibidem, p. 138) - temos que nos contentar apenas com o sentido:

É possível que uma sentença como um todo tenha tão-somente um sentido, mas nenhuma referência? De qualquer forma, poder-se-ia esperar que tais sentenças existam, do mesmo modo que há partes de sentenças que possuem sentido, mas que carecem de referência. São desta espécie as sentenças que contém nomes próprios sem referência. A sentença “Ulisses profundamente adormecido foi desembarcado em Ítaca" tem, obviamente, um sentido. Mas, assim como é duvidoso que o nome "Ulisses", que aí ocorre, tenha uma referência, assim também é duvidoso que a sentença inteira tenha uma. (Ibidem, p. 137).

Uma expressão, portanto, pode ser sentido mesmo não possuindo referência, ou seja, nada denotando no mundo. Mas, nesse caso, a sentença não possui valor-deverdade. Por essa razão, proposições fregeanas são ditas independentes-do-objeto, pois são inteiramente compostas de Sinn, e assim, o conteúdo mental também é independentedo-objeto. ${ }^{10}$ Uma segunda tese semântica, dessa forma, pode ser destacada:

\footnotetext{
${ }_{8}$ Neste sentido, não havendo pensamento singular, todo o conhecimento ocorre, diferentemente de Russell, por descrição, o que parece muito pouco plausível. Não explica, por exemplo, uma crença perceptiva. Outro problema do descritivismo semântico é que ele é vulnerável a uma série de contra-exemplos apresentados por Kripke (1980), entre outros. Por isso, Evans rejeita essa leitura descritivista em prol de uma associada a atitudes proposicionais, conforme veremos no próximo capítulo deste artigo.

9 O valor semântico de uma sentença é determinado pelo valor semântico das expressões que nela ocorrem.

10 Uma vertente não-fregeana de proposição independente-do-objeto, a chamada descritivista, é sustentada por Schiffer (1978) e Searle (1983). Ela concebe o pensamento singular como sendo um conteúdo descritivo, portanto, sentido fregeano, mas incorpora a ideia de Russell de que nomes são descrições abreviadas. A referência de um objeto se dá se ele satisfaz determinadas propriedades descritas. Mesmo que nenhum objeto instancie essas propriedades, ainda assim há pensamento. Essa posição é criticada por Kripke (1980). Outra vertente, neorrusselliana, afirma que proposições contém o objeto de referência, mas que ele pode ser apreendido por sentidos ou modos de apresentação (KAPLAN, 1989, PERRY, 1993).
}

SALATIEL, José Renato. Evans sobre Scheingedanke. Griot : Revista de Filosofia, Amargosa - BA, v.19, n.2, p.7186, junho, 2019. 


\section{Tese (2): Uma proposição singular pode ter sentido mesmo sem possui valor semântico.}

A questão que irá motivar os trabalhos de Evans a respeito dessa filosofia da linguagem proposta por Frege é que dificilmente proposições contendo termos singulares demonstrativos podem ser acomodadas na perspectiva teórica apresentada em "Sobre o sentido e a referência" (cf. EVANS, 1985). Pois se enunciados com o mesmo sentido (Sinn) devem possuir o mesmo valor semântico (Bedeutung), ao custo de não haver entendimento da linguagem pública, como deve ser compreendida uma sentença como "Hoje faz frio" ou "Eu estou com febre", quando os pronomes demonstrativos "hoje" e "eu" podem denotar indivíduos diferentes e, assim, possuir diferentes valores-deverdade?

\section{Pensamentos aparentes: Evans}

Evans (1982) e McDowell (1998) propuseram uma teoria de proposições neofregeanas de re, isto, é dependentes-do-objeto, cuja estrutura contém apenas sentido. $\mathrm{O}$ conteúdo de um pensamento singular seria completamente conceitualizado e, ainda assim, dependente-do-objeto, uma vez que somente pode haver um modo de apresentação do objeto se esse objeto de referência da proposição, de fato, existir. Duas reflexões filosóficas mais amplas motivam esses autores, uma de ordem semântica, a saber, o externalismo sobre o conteúdo mental; e outra epistemológica, relacionada ao acesso epistêmico ao mundo externo mediante a percepção.

Tanto Evans quanto McDowell rejeitam, assim, a concepção cartesiana de mente e do conhecimento que subjazem a teoria da proposição de Russell. De acordo com ela, o sujeito não pode estar enganado sobre os próprios pensamentos, uma vez que acessa somente dados sensórios. Mas, ao dirigir-se a objetos externos, abre-se a possibilidade de ter pensamentos ilusórios quando o objeto em questão não existe. Tais características, externalismo semântico e acesso epistêmico, são providos pela teoria das proposições singulares delineada em The Varieties of Reference, que, em particular, propõe acomodar termos singulares demonstrativos na teoria dos sentidos de Frege. $O$ principal argumento de Evans é o seguinte:

(1) Sentido é o modo de apresentação do objeto (Tese 1).

(2) Sentido é o pensamento expresso na sentença.

(3) Se não há se não há objeto, não há modo de apresentação (sentido) (Nega Tese 2).

(4) Se não há sentido, não há pensamento.

(5) Portanto, uma proposição singular é dependente-do-objeto.

A premissa (3) do argumento é a mais controversa. Nela, Evans refuta - ou restringe - a tese fregeana de que podem haver sentenças contendo nomes sem portadores que, apesar disso, expressam um pensamento. Frege, como vimos, é explícito

SALATIEL, José Renato. Evans sobre Scheingedanke. Griot : Revista de Filosofia, Amargosa - BA, v.19, n.2, p.7186, junho, 2019. 
em seus escritos quanto a esse ponto. E, para Evans, essa seria a inconsistência a ser superada na obra de Frege: ao mesmo tempo em que defende a tese de que sentido é o modo de apresentação de um objeto, (Frege) considera plausível haver sentido quando não há objeto algum denotado.

O primeiro ponto a ser examinado é a proposição (1): o sentido é o modo de apresentação do objeto. Disso Evans infere outra, subjacente (1a): deve haver, portanto, um objeto (referente) a ser apresentado pelo sentido, em outras palavras, a ser pensado. Pois considere o seguinte exemplo em Frege (PMC, p. 80), citado por Evans (1982, p. $15)^{11}$ :

(1) Alpha tem ao menos 5 mil metros de altura.

(2) Alpha = Ateb.

(3) Ateb tem ao menos 5 mil metros de altura.

"Alpha" e "Ateb" são nomes próprios que designam o mesmo objeto e, pelo princípio de substitutividade ${ }^{12}$, o argumento deveria ser válido. Contudo, a conclusão pode receber um valor de verdade falso, sem ser contraditório. $O$ que explicaria essa diferença cognitiva é o Sinn: dois modos diferentes de apresentação do objeto, "Alpha" e "Ateb". Segundo Evans, a ideia aqui é a de que:

\begin{abstract}
Alguém que ouça e entenda o enunciado de uma sentença contendo um termo singular, tal como 'Alpha tem mais de 5 mil metros de altura', deve ao menos pensar sobre a montanha - tendo, precisamente, este pensamento: que o que o falante diz a verdade se, e somente se, aquela montanha tem 5 mil metros de altura (Ibidem, p. 16).
\end{abstract}

Evans faz uma leitura de Frege em um contexto comunicacional, próximo à interpretação de Dummett (1978) para a teoria dos sentidos, e associa a noção de valor cognitivo à de atitudes proposicionais em psicologia (Ibidem, p. 18-19). A proposta de Frege, diz Evans, é a de que " [...] para que entendamos enunciados que o contenham [o termo singular] temos que não somente pensar um objeto particular, seu referente, mas pensar esse objeto de um modo particular" (Ibidem). Somente assim o conteúdo mental é finamente granulado o suficiente para que dois falantes competentes da linguagem possam ter a mesma atitude proposicional sobre a mesma sentença. ${ }^{13}$ Para isso, esses usuários competentes da linguagem não devem somente pensar um objeto - o referente de um nome próprio -, mas pensar esse objeto de um modo particular (Ibidem). Nestes

\footnotetext{
11 Evans data esse texto, estrategicamente, "em torno de 1914", apesar de ele não ser datado.

12 A substituição do constituinte de uma sentença por outro com o mesmo valor semântico deixa inalterado o valor semântico da sentença.

13 Evans chama essa concepção de Critério Intuitivo de Diferença: “[...] o pensamento associado a uma sentença S como seu sentido deve ser diferente do pensamento associado a outra sentença S' como seu sentido, se for possível para alguém entender ambas as sentenças, num dado instante, enquanto coerentemente adota diferentes atitudes proposicionais em relação a elas, i.e., aceitando (rejeitando) uma enquanto rejeita (aceita), ou é agnóstico sobre, a outra" (EVANS, 1982, p, 18-19). Entretanto, esse critério, por si só, não explicaria sentenças com termos singulares demonstrativos como "Hoje está chovendo", conforme veremos adiante.
}

SALATIEL, José Renato. Evans sobre Scheingedanke. Griot : Revista de Filosofia, Amargosa - BA, v.19, n.2, p.7186, junho, 2019. 
termos, faz sentido pensar um modo de apresentação de um objeto quando não há objeto algum a ser pensado? Em outras palavras, como Evans coloca, que sentido faz pensar uma crença sobro mundo que não possui valor-de-verdade, isto é, que não certa e nem errada? (Ibidem, p. 24).

Frege, conforme visto, admite que sentenças que contenham termos singulares vazios podem, ainda assim, terem Sinn em um contexto apropriado (ficcional). Esta posição, contudo, é inconsistente com sua semântica, segundo Evans, além de associar de forma equivocada todo termos singular vazio a um uso poético da linguagem (Ibidem, p. 28). O ponto principal de sua argumentação é que essa inconsistência desaparece caso seja contextualizada na seguinte passagem, na qual Frege contrapõe pensamentos genuínos, atribuídos a sentenças que podem ser verdadeiras ou falsas, a pensamentos simulados (mock thouhts), ${ }^{14}$ que decorrem de enunciados ficcionais:

Nomes que falham em cumprir seu papel usual de um nome próprio, que é o de nomear algo, podem ser chamados de nomes próprios simulados [mock proper names]. Apesar do conto sobre William Tell ser uma lenda, não história, e do nome "William Tell" ser um nome próprio simulado [mock proper name], não podemos negá-lo um sentido. Mas o sentido da sentença "William Tell atirou numa maça sob a cabeça de seu filho" não é mais verdadeiro do que o da sentença "William Tell não atirou numa maça sob a cabeça de seu filho". Eu não posso dizer, porém, que esse sentido tampouco é falso, mas o caracterizo como fictício [...]. Ao invés de falar de "ficção", podemos falar de pensamentos simulado [mock thoughts]. Assim, se o sentido de uma sentença assertórica não é verdadeiro, ele é falso ou fictício, e será, em geral, o último, se ela contiver um nome próprio simulado [mock proper name]. (PW, p. 130).

Nota-se que Frege inicia a citação tratando de casos em que nomes próprios não cumprem sua função de denotar um referente. Nestes casos, diz, o nome próprio teria Sinn, não genuíno, mas apenas simulado. Em seguida, diz que, do mesmo modo, sentenças que conteriam esses nomes próprios simulados não teriam valor-de-verdade, ou seja, não seriam nem verdadeiras e nem falsas. $O$ sentido seria apenas simulado nesses contextos. Evans então conclui que:

Sim: uma sentença contendo um termo singular vazio pode ter um sentido, e nisso ela não tem que ser, necessariamente, comparada com uma sentença contendo uma palavra sem significado [nonsense word]. Mas não: ela não tem realmente sentido do tipo possuído por sentenças atômicas ordinárias, porque ela não funciona corretamente, é somente como se funcionasse corretamente. (EVANS, 1982, p. 30).

Para Evans, aqui Frege quer dizer que uma proposição singular sem valor semântico expressa um sentido, e nisso ela difere de uma proposição que não tenha significado, como em "Ideias verdes incolores dormem furiosamente". No entanto, esse

\footnotetext{
14 Optamos pelas seguintes traduções de Scheingedanke: quando usado por Frege, na tradução do inglês para mock thoughts, usaremos pensamento simulado; quando usada no contexto de Evans, traduziremos por pensamentos aparentes, seguindo a proposta deste autor.
}

SALATIEL, José Renato. Evans sobre Scheingedanke. Griot : Revista de Filosofia, Amargosa - BA, v.19, n.2, p.7186, junho, 2019. 
pensamento expresso não é o mesmo no caso de uma proposição singular que cumpre seu propósito de veicular uma crença empírica.

O problema, diz, é que Frege restringiria esses cenários de mock thoughts a contextos ficcionais, nos quais o falante competente da linguagem conhece as regras e sabe que, ali, não se aplicam as mesmas que em contextos científicos. Frege, no mesmo texto, é claro sobre isso: "Se o Don Carlos, de Schiller fosse considerado uma peça histórica, então o drama seria, em grande medida, falso. Mas uma obra de ficção não deve ser tomada, de modo algum, seriamente: é tudo um jogo" (PW, 130).

O que Evans sugere, ao contrário, é que mock thoughs devem ser entendidos como pensamentos aparentes ou ilusórios, aplicados a categorias específicas de proposições singulares, ${ }^{15} \mathrm{em}$ contextos diversos da ficção, nos quais, quando os termos singulares são vazios, há apenas a ilusão de pensamento e de entendimento (EVANS, 1982, p. 31). Que cenários seriam esses?

Para Evans, não são cenários de ficção, mas cenários epistêmicos, de ilusões ou alucinação a respeito do objeto de percepção. Assim como Strawson (1990), Evans entende que, aquilo que ele chama de termos singulares demonstrativos genuínos, expressos em sentenças como "Este corpo" ou "Aquele homem", só podem ser compreendidos em uma comunicação e expressar pensamentos quando enunciados em situações de efetiva percepção dos referentes: " [...] a ideia geral é que pensar sobre um objeto demonstrativamente é pensar sobre um objeto de um modo que crucialmente depende do sujeito, naquele instante, perceber aquele objeto" (EVANS, 1982, p. 72). ${ }^{16}$

Para ele, portanto, há duas condições que satisfazem a semântica de sentenças que contém termos singulares: (i) essas expressões devem ser acompanhadas da percepção do objeto de referência desses termos; e (ii) o pensamento expresso nesses enunciados depende dessa relação sensório-perceptiva com o objeto (Ibidem). Assim, caso a condição (ii) não seja atendida, pode-se dizer que estamos em um cenário de pensamentos aparentes (Scheingedanke), onde o sujeito não tem um pensamento singular genuíno, apenas aparente.

O ponto é $[. .$.$] que, no caso em que o sujeito percebe um objeto, está disponível$ a ele um pensamento com um conteúdo de um certo tipo, e nenhum pensamento com um conteúdo deste tipo está disponível quando não há nenhum objeto que o sujeito esteja percebendo. Dado que é um pensamento com este tipo de conteúdo que é requerido para entender uma sentença contendo um termo singular demonstrativo genuíno, podemos juntar os pontos e concluir que, quando tal termo, conforme usado, é vazio, nada conta como entendimento do que o falante disse. (Ibidem, p. 73; cf. p. 136 e 176).

\footnotetext{
15 Há dois casos nos quais justifica-se pensamento em sentenças que contenham termos singulares vazios: descrições definidas, nas quais Evans aceita a teoria de Russell, que as trata como expressões quantificadas complexas (EVANS, 1982, p. 53); e nomes descritivos, cuja referência é estipulada, como no exemplo "Vamos chamar quem quer que tenha inventado o zíper de Julius" (Ibidem, p. 31 e 49-50), na qual há pensamento efetivo numa sentença como "Júlio era inglês", mesmo que não haja referente para o nome próprio "Júlio".

16 Evans, em particular, elabora uma teoria segundo a qual pensamentos singulares são baseados em percepção, memória e testemunho. Por esta razão, não bastaria a teoria dos sentidos para explicar do funcionamento de enunciados deste tipo (cf. nota 12 deste artigo).
}

SALATIEL, José Renato. Evans sobre Scheingedanke. Griot : Revista de Filosofia, Amargosa - BA, v.19, n.2, p.7186, junho, 2019. 
As frases "certo tipo" e "deste tipo" são importantes, pois enfatizam que não ter um conteúdo mental do tipo "singular" não significa não ter nenhum conteúdo mental. Outro aspecto a se destacar é que, quando há apenas pensamento aparente, a sentença não é inteligível, não por não ter nenhum significado, mas por representar uma crença empírica que nada pode afirmar acerca do mundo. $O$ argumento, assim, pode ser parafraseado como: se uma proposição contendo um termo singular demonstrativo genuíno expressa um pensamento (Sinn), quando esse termo singular é vazio, ou seja, sem portador, não há pensamento do tipo singular (genuíno) mas apenas a ilusão de pensamento ou pensamento aparente (Scheingedanke).

\section{Críticas a Evans}

O problema com o argumento de Evans é que ele, definitivamente, não pode ser atribuído tout court à filosofia da linguagem de Frege, e tampouco sua refutação torna a semântica fregeana inconsistente. A literatura especializada é consensual a esse respeito, em particular os trabalhos de Bell (1990), Geirsson (2002) e Sainsbury (2002). Na análise que segue, o foco será a teoria do sentido e o conceito de Scheingedanke, desconsiderando demais tópicos investigados por esses autores nos referidos trabalhos.

É importante para Evans, em primeiro lugar, interpretar a metáfora "modos de apresentação" do objeto de referência como "modos de pensar" o objeto de referência, e daí concluir que, não havendo objeto algum a ser "apresentado" pelo Sinn, não haveria pensamento. Para Bell (1990, p. 274), contudo, essa leitura não é compatível com os textos de Frege. Por um lado, o autor é explícito a respeito de que "[...] apreender o sentido nunca assegura a existência de sua referência" (FREGE, 2009a, p. 133). Por outro, Bell sugere a substituição a metáfora pelo termo condição, que seria mais preciso para explicar o sentido, com base em passagens de Frege como a seguinte:

[...] não somente uma referência, mas também um sentido pertence a todos os nomes corretamente formados a partir de nossos signos. Cada sentença expressa um sentido, um pensamento. Pois, dadas nossas estipulações, são determinadas sob quais condições se refere ao Verdadeiro. $O$ sentido de um nome, o pensamento, é: que essas condições são satisfeitas (FREGE, 2016, p. $50)$.

Sentido, nestes termos, é a condição dada pelo signo que um indivíduo deve satisfazer para ser sua referência. E assim, diz Bell, é plausível haver condições que não são satisfeitas por nenhum indivíduo ou objeto, dissipando assim, uma suposta inconsistência na semântica fregeana (BELL, 1990, p. 275). Na mesma linha, Sainsbury sugere que, para evitar equívocos, "[...] deveríamos abandonar os modos de apresentação como uma contribuição séria para o entendimento do sentido fregeano" (2002, p. 10). ${ }^{17}$ Geirsson, por seu turno, afirma ser suficiente as indicações que Frege

17 De fato, Sainsbury sugere, no ensaio "Sense without reference" (SAINSBURY, 2002, p. 205 e ss.), uma interpretação próxima a de Bell a respeito de condições a serem satisfeitas pelo Bedeutung.

SALATIEL, José Renato. Evans sobre Scheingedanke. Griot : Revista de Filosofia, Amargosa - BA, v.19, n.2, p.7186 , junho, 2019. 
fornece em "Sobre o sentido e referência" sobre sentido associado a nomes vazios (2002, p. 307$).{ }^{18}$

Frege, não obstante, não é claro o suficiente em suas definições de Sinn e o uso de metáforas como "modos de apresentação", ou mesmo se a sua substituição por condições é mais próximo do que ele pretendia ao relacionar o termo com Bedeutung. Ele é claro em dizer que expressões sem valor semântico possuem sentido. A questão, entretanto, é que Evans não nega isso: ele apenas diz que "[...] não há absolutamente nada em sua teoria semântica que o impeça de reconhecer termos singulares russelianos" (EVANS, 1982, p, 38; cf. 1985, p. 300). ${ }^{19}$ Acerca disso, a concepção de pensamentos aparentes não creditaria a Evans evidências em favor de sua posição? Para os três autores aqui analisados, não: a ideia de pensamentos aparentes também não se sustentaria diante uma leitura mais atenta de Frege.

De acordo com Bell, Evans erra ao misturar questões relativas à inteligibilidade e à assertividade de uma sentença contendo um termo singular, ou seja, quando, em uma proposição, o nome não possui valor semântico, ela não seria asserível e sequer inteligível (BELL, 1990, p. 273). As seguintes afirmações a respeito de uma proposição na forma "a é F", diz Bell (Ibidem, p. 272-273), podem ser creditas a Frege, sem maiores problemas:

1) Ela não pode ser usada "seriamente" ou "cientificamente" em uma comunicação, seja para "expressar conhecimento" ou "informar".

2) Ela não possui valor-de-verdade.

3) Ela expressa somente um pensamento simulado (mock).

4) Ela não pode ser o conteúdo de um juízo ou uma crença, uma vez que o sujeito esteja consciente da não existência de "a".

A essas afirmações, Evans acrescentaria, equivocadamente segundo Bell, uma quinta:

5) Ela não tem sentido (sensesless), isto é, não veicula nenhum pensamento na forma "S P a é F", onde usamos $\mathrm{P}$ para uma atitude proposicional;

A afirmação (5), diz, seria baseada em "tradução equivocada" e "indevida" de Scheingedanke. Pois a distinção feita por Frege seria entre (a) pensamentos genuínos: aqueles que podem ser asseríveis "seriamente ou cientificamente" e, portanto, possuem valor-de-verdade e, consequentemente, referentes em seus elementos constituintes; e pensamentos simulados: aqueles que não podem ser tomados seriamente, ou seja, que não possuem valor-de-verdade e referência. "A tradução de "Scheingedanke' como "mock

\footnotetext{
18 Geirsson cita o caso de descrições definidas, que Frege (2009a, p. 133) usa em seus exemplos de nomes vazios ("o corpo celeste mais distante da Terra" e "a série que converge mais rapidamente") para refutar Evans. Não é, porém, um bom exemplo, pois Evans considera descrições definidas exceções à sua teoria da referência.

${ }^{19}$ Salienta-se que nem sempre Evans demonstra fazer uma leitura muito tolerante de Frege, cujas formulações aponta serem "qualificadas e equivocadas" (1982, p. 14), "pouco inteligível(is)" (Ibidem, p. 23) e com "enorme(s) falha(s)" (Ibidem, p. 24) e "inconsistente(s)" (Ibidem, p. 28 e 29).
}

SALATIEL, José Renato. Evans sobre Scheingedanke. Griot : Revista de Filosofia, Amargosa - BA, v.19, n.2, p.7186, junho, 2019. 
thoughts' é indevida, pois implica, injustamente, que Scheingedanke não é mais um pensamento genuíno que um simulado (mock)" (Ibidem, p. 273), quer dizer, não é pensamento de forma alguma.

Compare com o que diz Sainsbury (2002, p. 11):

Segundo minhas sondagens junto a falantes nativos, uma sentença-Schein é, comumente, algo que intenciona parecer uma sentença, mesmo quando não o é [...]. Penso que, neste contexto, Frege usa "mock" (ou melhor, "schein") de tal modo que uma sentença-mock é uma sentença que não deve ser tomada seriamente.

Essa passagem corrobora com Bell a respeito de um pensamento simulado ter, ainda, um determinado conteúdo mental, ainda que seja um que não deva ser asserível, conforme diz Frege, em contextos científicos. "Enquanto é verdadeiro que uma asserção simulada (mock) não é uma asserção, não é por isso que uma sentença fingida não é, em geral, uma sentença”, pois "uma expressão não-asserível pode exprimir um pensamento, independentemente de ela ser ou não tomada seriamente" (Ibidem, p. 12). ${ }^{20}$

Geirsson (2002) corrobora com essa leitura. Para ele, Frege é claro nos seguintes pontos: (i) a diferença entre um pensamento legítimo e um pensamento simulado (mock thought) é que os primeiros cumprem sua função semântica e têm valor-de-verdade (Bedeutung), enquanto o segundo, não. Do mesmo modo, um nome próprio difere de um nome simulado (mock name) pelo fato do primeiro ter referente, enquanto o segundo é vazio (2002, p. 309); (ii) há pensamento mesmo quando uma sentença não possui valor semântico, ainda que seja um pensamento literário ou mitológico, inadequado para o uso em contexto de conhecimento científico (Ibidem, p. 310). Segundo Geirsson, não podemos atribuir a Frege, portanto, a ideia de que pensamentos simulados não são pensamentos, que eles não são "reais", no sentido de não existirem de forma alguma.

Em síntese, haveria dois motivos, de ordem exegética, contrários ao argumento de Evans em favor de uma leitura russeliana de Frege. Primeiro, a teoria dos sentidos não é, necessariamente, inconsistente com a teoria da referência de Frege, observando-se outras definições de Sinn que evitem a metáfora de "modo de apresentação" do objeto. Além disso, pensamentos simulados (mock tought) não se contrapõe a pensamento efetivo ou real. É possível, pois, para sentenças contendo termos singulares vazios, expressarem pensamentos, ainda que não valor semântico. E, deste modo, a teoria de proposições neofregeanas de re e a teoria dos pensamentos aparentes que lhe confere fundamento, seriam incompatíveis com uma leitura mais acurada de Frege.

20 A passagem em que Frege fala de asserções simuladas (mock) está no mesmo contexto no qual ele fala de pensamentos simulados: “Asserções em ficção não devem ser levadas a sério: elas são somente asserções simuladas. Mesmo os pensamentos não devem ser levados a sério como o seriam em ciências: eles são apenas pensamentos simulados. Se Don Carlos, de Schiller, fosse considerado uma peça histórica, então grande parte do drama seria falsa. Mas uma obra de ficção não é para ser levada a sério de modo algum: é tudo um jogo..." (PW, p. 130).

SALATIEL, José Renato. Evans sobre Scheingedanke. Griot : Revista de Filosofia, Amargosa - BA, v.19, n.2, p.7186, junho, 2019. 


\section{Considerações finais}

Os trabalhos de Bell, Greisson e Sainsbury compõem uma objeção fundamentada, em evidências textuais, contra a doutrina do pensamento singular proposta por Evans. Porém, creio que são insuficientes para creditá-la como "indefensável" (BELL, 1990, p. 268), “implausível” (GEIRSSON, 2002, p. 311) ou "pouco persuasiva(s)" (SAINSBURY, 2002, p. 14).

Em específico, destaco três concepções atribuídas a Evans que, creio, desvirtuam a proposta teórica do autor: (i) ao asserir uma proposição singular aparente, o sujeito estaria consciente de usar um termo singular sem portador (BELL, 1990, p. 272); (ii) pensamento aparente se opõe a pensamento real por ser vazio de conteúdo (BELL, 1990, 273). (iii) que pensamento aparente é pensamento sem sentido, em outras palavras, Evans confundiria assertibilidade com inteligibilidade em Frege (BELL, 1990, p. 272 e 273; GEIRSSON, 2002, p.308 e 309, SAINSBURY, 2002, p. 12).

Sobre o primeiro ponto, fica claro que cenários céticos em Evans não envolvem, necessariamente, um desvio consciente da função semântica de termos singulares, mas erros de cognição, como alucinação ou ilusão. "Se não há nenhum objeto ao qual o sujeito, de fato, está em 'contato' informacional - se ele está alucinando ou se vários objetos diferentes se sucedem sem que ele se dê conta - então ele não tem [...] pensamento" (EVANS, 1982, p. 173).

Em segundo lugar, o argumento de Evans para pensamentos singulares dependentes-de-objetos é um caso que envolve, eminentemente, termos singulares demonstrativos e cenários epistêmicos de ilusão ou alucinação. Quando o sujeito crê estar diante o objeto referido, mas nada há, ele não pode ter um pensamento apropriado, mas apenas aparente. Isso no sentido de não ter pensamento nenhum "daquele tipo", o que não significa que sua mente esteja "vazia". Nesta citação, na qual contrapõe sua teoria à perspectiva cartesiana de Russell, ele deixa isso explícito:

[...] não me parecer ser nada incoerente a ideia de que um sujeito pode, justamente por pensar estar tendo um pensamento sobre um (digamos) objeto físico que ele visualiza, e ainda assim, precisamente porque não há nenhum objeto que ele veja, falhar em ter o pensamento do tipo que ele supõe ter. Não é parte da minha proposta que sua mente é completamente vazia; imagens e palavras podem passar por ela, e mesmo vários pensamentos auxiliares podem lhe ocorrer. (EVANS, 1982, p. 44).

Por fim, Evans não interpreta mal a obra de Frege e nem faz uma tradução equivocada de Scheingedanke (cf. McDOWELL, 2009, p. 179 e p. 183 n. 40). Pelo contrário, Evans estava ciente de que, em contextos específicos de ficção, nas quais o sujeito tem consciência de estar usando nomes próprios sem portadores, há Sinn, ainda que Schein. ${ }^{21}$ Para ele não poderia haver sentido em enunciados do tipo expresso por proposições contendo termos singulares demonstrativos, que perfazem um cenário

${ }^{21}$ Além disso, pare ele nomes fictícios ou mitológicos poderiam ser resolvidos pela teoria das descrições.

SALATIEL, José Renato. Evans sobre Scheingedanke. Griot : Revista de Filosofia, Amargosa - BA, v.19, n.2, p.7186, junho, 2019. 
diferente daquele proposto por Frege. Evans é claro a respeito disso em várias passagens:

\begin{abstract}
A afirmação é simplesmente de que há um tipo de pensamento que às vezes temos, tipicamente expresso na forma "O $G$ é $F$ ", e que podemos objetivar ter pensamento deste tipo, quando, em virtude da ausência de qualquer objeto apropriado, não há tal pensamento. (EVANS, 1982, p. 46).

Para entender sentenças envolvendo termos da categoria em questão é requerido que a audiência tenha um tipo particular de pensamento [...]. E, em segundo lugar, [...] que pensamentos deste tipo requeridos são russelianos eles simplesmente não estão disponíveis para serem pensados nas circunstâncias nas quais não há objeto (nenhum referente) (Ibidem, p. 72; cf. p. 73).
\end{abstract}

Em nenhuma dessas citações Scheingedanke é usado no mesmo registro teórico que Frege. Evans fala de uma situação diferente, quando se refere a um "tipo" ou "categoria" específica de pensamento singular, que exige contato direto, via percepção, com o objeto de referência e que tem como propósito expressar uma crença empírica. É somente nesses casos que, na ausência do Bedeutung, há o que podemos chamar de cenários de pensamentos aparentes. Penso, assim, que sua teoria do pensamento singular pode ser lida como uma tentativa de reformulação das ideias de Frege, ainda que pouco ortodoxa (McDOWELL, 2009). ${ }^{22} \mathrm{E}$ que a teoria dos pensamentos aparentes seria melhor problematizada em um viés epistemológico: faz sentido falar em cenários de pensamentos aparentes?

\footnotetext{
22 "Evans insiste que a concepção de Sinn em Frege pode ser entendida de modo a adaptar-se a pensamentos dependents-do-objeto, e isso sustenta-se independentemente da especulação sobre a atitude de Frege a respeito de tal ideia. Isto deve ser salientado. No fim, é a ideia de Sinn dependente-do-objeto que importa, não se ela pode ou não ser atribuída ao próprio Frege" (McDOWELL, 2009, p. 179).
}

SALATIEL, José Renato. Evans sobre Scheingedanke. Griot : Revista de Filosofia, Amargosa - BA, v.19, n.2, p.7186, junho, 2019. 


\section{Referências:}

BACK, Kent. Thought and reference. Oxford: Clarendon Press, 1987.

BELL, David. How Russellian was Frege? Mind, v. 99, n. 394, p. 267-277, Apr. 1990

DUMMETT, Michael. Frege's distinction between sense and reference. In: Truth and other enigmas. Cambridge, Mass.: Harvard University Press, 1978.

EVANS, Gareth. The varieties of reference. Oxford: Oxford University Press, 1982.

EVANS, Gareth. Understanding demonstratives. In: EVANS, Gareth. Collected papers. Oxford: Clarendon Press, 1985.

FREGE, Gottlob. Posthumous Writings. HERMES, Hans; KAMBARTEL, Friedrich; KAULBACH, Friedrich (eds.). Trans.: Peter Long; Roger White. Oxford: Basil Blackwell, 1979. [Citado como PW.]

FREGE, Gottlob. Philosophical and Mathematical Correspondence. GABRIEL, Gottfried et al (eds.). Trans.: Hans Kaal. Oxford: Basil Blackwell, 1980. [Citado como PMC.]

FREGE, Gottlob. O pensamento. Uma investigação lógica. In: Investigações lógicas. ALCOFORADO, Paulo (Org., trad. e notas). Porto Alegre: EDIPUCRS, 2002, p. 11-39. FREGE, Gottlob. Sobre o sentido e a referência. In: FREGE, Gottlob. Lógica e Filosofia da Linguagem. Seleção, introdução, tradução e notas: Paulo Alcoforado. 2. ed. amp. e rev. São Paulo: Unesp, 2009a. p. 129-158.

FREGE, Gottlob. Dezessete sentenças básicas da lógica. In: FREGE, Gottlob. Lógica e Filosofia da Linguagem. Seleção, introdução, tradução e notas: Paulo Alcoforado. 2. ed. amp. e rev. São Paulo: Unesp, 2009b. p. 207-209.

FREGE, Gottlob. Basic Laws of Arithmetic. Derived using concept-script. Vols. I \& II. Transl. and ed. Philip A. Ebert; Marcus Roosberg; Crispin Wright. New York, NY: Oxford University Press, 2016.

GEIRSSON, Heimir. Frege and object dependent propositions. Dialectica, v. 56, n. 3, p. 299-314, 2002.

JESHION, Robin. Introduction. In: JESHION, Robin (Ed.). New essays on singular thought. Oxford: Oxford University Press, 2010.

KAPLAN, David. Demonstratives: an essay on the semantics, logic, metaphysics, and epistemology of demonstratives and other indexicals. In: ALMOG, Joseph; PERRY, John and WETTSTEIN, Howard (eds.). Themes from Kaplan. New York: Oxford University Press, 1989, p. 481-564.

KRIPKE, Saul. Naming and Necessity. Cambridge, Mass.: Harvard University Press, 1980.

McDOWELL, John. [1984] De re senses. In: McDOWELL, John. Meaning, knowledge, and reality. Cambridge, Mass.; London, England. Harvard University Press, 1998. p. 214-227.

McDOWELL, John. Evans's Frege. In: McDOWELL, John. The engaged intellect: philosophical essays. Cambridge; London: Harvard University Press, 2009. p. 163-185. PERRY, John. The problem of essential indexical: and other essays. New York/ Oxford: Oxford University Press, 1993.

SALATIEL, José Renato. Evans sobre Scheingedanke. Griot : Revista de Filosofia, Amargosa - BA, v.19, n.2, p.7186, junho, 2019. 
RUSSELL, Bertrand. [1917]. Conhecimento por familiaridade e conhecimento por descrição. In: RUSSELL, Bertrand. Misticismo e lógica; e outros ensaios. Tradução de Alberto Oliva e Luiz Alberto Cerqueira. Rio de Janeiro: Zahar, 1977. p. 215-236. RUSSELL, Bertrand. Da denotação. [1905]. In: RUSSELL, Bertrand. Lógica e conhecimento: ensaios escolhidos. Col. Os Pensadores. 3. ed. Tradução de Pablo Rubén Mariconda. São Paulo: Nova Cultural, 1989a.

RUSSELL, Bertrand. [1918]. A Filosofia do atomismo lógico. In: RUSSELL, Bertrand. Lógica e conhecimento: ensaios escolhidos. Col. Os Pensadores. 3. ed. Tradução de Pablo Rubén Mariconda. São Paulo: Nova Cultural, 1989b.

SAINSBURY, R. M. Departing from Frege: essays in the philosophy of language. London and New York: Routledge, 2002.

SCHIFFER, Stephen. The basis of reference. Erkenntnis, v. 13, n. 1, p. 171-206, 1978. SEARLE, John. Intentionality. Cambridge: Cambridge University Press, 1983.

STRAWSON, Peter Frederick. Individuals: an essay in descriptive metaphysics. London: Routledge, 1990.

Autor(a) para correspondência: José Renato Salatiel, Universidade Federal do Espírito Santo, Av. Fernando Ferrari, 514, - IC II - Térreo - Secretaria Integrada dos Departamentos(Sala 1), Goiabeiras, 29075-910, Vitória - ES.jose.salatiel@ufes.br

SALATIEL, José Renato. Evans sobre Scheingedanke. Griot : Revista de Filosofia, Amargosa - BA, v.19, n.2, p.7186, junho, 2019. 